\title{
SITUAÇÃO DE ESTUDO (SE) RELAÇÕES BIÓTICAS E ABIÓTICAS EM UMA MATA: DA SUA ELABORAÇÃO A IMPLEMENTAÇÃO NO ENSINO FUNDAMENTAL
}

\section{Study Situation (SS) Biotic and abiotic relationships in a wood: from its elaboration to its implementation on the Elementary School}

\author{
Lílian Corrêa Costa-Beber (liliantutty@ hotmail.com) \\ Programa de Pós-Graduação Stricto Sensu em Atenção Integral à Saúde, Universidade Regional do \\ Noroeste do Estado do Rio Grande do Sul (UNIJUÍ). \\ Vidica Bianchi (vidica.bianchi@unijui.edu.br) \\ Departamento de Ciências da Vida (DCVida), Programa de Pós-Graduação Stricto Sensu em Educação \\ nas Ciências, Universidade Regional do Noroeste do Estado do Rio Grande do Sul (UNIJUÍ).
}

Resumo: A Situação de Estudo (SE), enquanto proposta para mudança curricular, pode contribuir para a formação dos alunos enquanto sujeitos críticos e ativos no seu aprendizado vinculado a um contexto real. Esse artigo considera a elaboração e implementação da SE "Relações bióticas e abióticas em uma mata" em turma de Ensino Fundamental, análise do feedback dos alunos e posterior reformulação na tríade de professores. A SE foi problematizada com a visita ao Bosque dos Capuchinhos (Ijuí, RS), seguida da realização do terrário, atividade chave nessa SE, que contribuiu para a retomada da problemática ambiental. Todo o processo foi interativo, possibilitou a percepção de conhecimentos prévios, e a necessidade de dosar os conteúdos conforme o tempo disponível. Foi preciso atenção as discussões geradas para adaptar a SE conforme as necessidades da turma, pois ela não é estática. Concluímos que a SE auxiliou na constituição dos alunos enquanto sujeitos ativos no seu aprendizado.

Palavras-chave: problematização; interação; aprendizagem.

Abstract: The Study Situation (SS), as proposition to curricular changes, can contribute to the students' formation, as critical and active subjects in their learning, linked with a real context. This article consider the elaboration and implementation of the SS "Biotic and abiotic relationships in a woodland" in a class of Elementary School, analysis of the students' feedback and later reformulation with the teachers' triad. The SS was problematized with a visit to the Capuchinhos' Woodland (Ijuí, RS), followed by the terrarium construction, a key activity in this SS, which contributed to the resumption of the environmental issues. The whole process was interactive, turned possible the perception of previous knowledge and the need of analyzing the study contents according to the available time. It was necessary to be aware to discussions to adapt the SS according to the class requirements, because the SS is not static tool. We conclude that the SS helped on the students' constitution as active subjects in their learning.

Keywords: problematization; interaction; learning. 


\section{INTRODUÇÃO}

Vivemos em uma era marcada pela industrialização, competição por recursos e tecnologias. O avanço tecnológico depende de pesquisa, a pesquisa depende de ensino, e o ensino exige mudanças curriculares.

Conforme os Parâmetros Curriculares Nacionais (PCN) de Ciências Naturais, é objetivo da Educação Básica formar pessoas que questionem a realidade, e capazes de encontrar soluções lógicas para os problemas que surgirem. Formar cidadãos assim demanda um ensino diferente do tradicional atualmente disponível, que é centrado na transmissão de conhecimentos sem, necessariamente, vinculá-los ao contexto e aos saberes extraescolares (COSTA-BEBER et al., 2014). Portanto, o avançar tecnológico requer revisão e reestruturação de currículos (PCN, 1998). Entende-se como reestruturação curricular um processo de rompimento de saberes incoerentes e fragmentados (MORIN, 2001).

Nessa perspectiva, no final dos anos 90 iniciaram os estudos para a implementação de uma alternativa de ensino, a Situação de Estudo (SE). A SE visou romper com a ideia simplista de currículo, na forma de "vencer a lista de conteúdos programáticos" (RITTER et al., 2018), em pró de um currículo envolvendo atividades estratégicas inseridas numa situação do cotidiano. A SE foi inicialmente criada pelo Grupo Interdepartamental de Pesquisa sobre Educação em Ciências (GIPEC). Ela apresenta-se como proposição curricular aberta, visando o desenvolvimento de atividades alternativas e o trabalho de conceitos através de uma visão contextualizada, rompendo a linearidade e fragmentação conceitual (VIEIRA et al., 2018). Trata-se de uma reorganização curricular fundada com base na abordagem histórico-cultural nas ideias de Vygotsky (2000) que potencializa os momentos em sala de aula, de modo que os conceitos são trabalhados a partir de uma situação, isto é, a partir de um contexto. Considerada inovadora e até exitosa, a SE além de atender as demandas dos PCN e do ensino como um todo, também atende as inovações propostas pela Base Nacional Curricular Comum (BNCC) (BRASIL, 2018).

Apesar de ser uma proposta de reorganização curricular rica, ainda são poucos os trabalhos disponíveis que tratam da elaboração e/ou implementação da SE (VIEIRA et 
al., 2018). Desse modo, é imprescindível a comunicação de resultados obtidos com a elaboração e/ou implementação de SEs sobre diferentes assuntos, a fim de fornecer recursos para outros professores endossarem a construção de um currículo inovador na área das Ciências Naturais.

Considerando as potencialidades da proposta de SE, pretendemos problematizar e propor coletivamente formas inovadoras de currículo, com especial atenção as exigências da BNCC (BRASIL, 2018). Nessa perspectiva, este artigo contempla o processo de elaboração e implementação da SE "Relações bióticas e abióticas em uma mata". Busca-se mostrar a constituição de um currículo integrado e as contribuições do processo interativo para a formação docente, com um olhar atento a problemática ambiental. Apresenta-se um conjunto de atividades, elaboradas coletivamente, que articulam as diferentes disciplinas e envolvem todos os sujeitos num processo de reflexão-interação-ação-reflexão.

\section{METODOLOGIA}

A presente pesquisa é qualitativa "não-estruturada e exploratória, baseada em pequenas amostras que proporcionam percepções e compreensão do contexto do problema" (MALHOTRA, 2006, p. 17).

A pesquisa consistiu de quatro momentos, a elaboração da SE por dois ou três sujeitos iniciais, sua implementação em sala de aula, análise do feedback dos alunos de Educação Básica, análise e posterior reformulação da SE através dos conhecimentos e sugestões fornecidas por estudantes da Educação Básica (SANGIOGO et al., 2013). Para melhor organização e fluidez da leitura do texto, optou-se por contemplar todo o processo de elaboração das três etapas da SE na metodologia, onde o leitor consegue ter acesso a metodologia em si e as obras embasaram o processo. Em seguida, traz-se como resultados o processo de implementação da SE, análise do feedback dos alunos e sua reconstrução, bem como sua conformação final.

\subsection{PRIMEIRO MOMENTO: ELABORAÇÃO DA SE}

A elaboração da SE considerou o objetivo do ensino de Ciências trazido pelos PCN (BRASIL, 1998, p. 19-20), que é "dar condições para o aluno vivenciar o que se 
denomina método científico, ou seja, a partir de observações, levantar hipóteses, testálas, refutá-las e abandoná-las quando fosse o caso, trabalhando de forma a redescobrir conhecimentos".

Os critérios seguidos para escolha do tema e conceitos abordados nem sempre são claros durante a elaboração das SEs, mas sempre aspectos da vivência dos alunos (HALMENSCHLAGER; SOUZA, 2012). Nesse caso, os conceitos foram previamente selecionados conforme o Plano de Trabalho da escola para os estudos de Ciências e adequados a SE. Na elaboração da SE participou um professor em formação inicial do curso de Licenciatura em Ciências Biológicas que reuniu os conceitos que deveriam ser trabalhados naquele trimestre letivo, as possíveis situações para estudo que poderiam englobar esses conceitos, e as melhores alternativas de atividades que poderiam ajudar a atender os objetivos.

A SE foi desenvolvida com o intuito de potencializar a formação de sujeitos ativos na construção do seu conhecimento, e capazes de refletir criticamente sobre conceitos científicos a luz de situações reais, numa perspectiva que possibilite uma visão global, ultrapassando a visão linear e fragmentada (BOFF et al., 2011). Para tal, ela foi estruturada em três etapas: problematização das questões, complexificação dos conceitos e sistematização do processo, considerando os pressupostos trazidos por Vygotsky (2000), segundo o qual o sujeito constrói e reconstrói o seu conhecimento mediante a inter-relação dinâmica em um contexto histórico-sócio-cultural.

\subsubsection{PRIMEIRA ETAPA: PROBLEMATIZAÇÃO}

A problematização pelo professor, como etapa inicial da SE, é fundamental, pois implica definir "prioridades" no ensino (definir o essencial do complementar), o que é ditado "[...] pelas condições da situação existencial concreta em que vive o homem" (SAVIANI, 2004, p. 39). Através dessa etapa, tem-se como intuito contextualizar o conteúdo, para possibilitar a percepção do científico em meio a realidade cotidiana (BEDIN; DEL PINO, 2017), incentivar os alunos a falar sobre aquilo que já é de seu conhecimento (HALMENSCHLAGER; SOUZA, 2012), e desmistificar alguns dos conceitos que serão trabalhados em sala de aula (GÜNZEL, 2019). 
Como a SE teve como tema as "Relações bióticas e abióticas em uma mata", e também tínhamos a intenção de promover a consciência crítica a luz da problemática ambiental, optou-se pela visita ao Bosque dos Capuchinhos (Ijuí/RS) como forma de problematizar e iniciar os trabalhos. Bosque é definido como uma área de vegetação arbórea remanescente, onde predominam arbustos e árvores, influenciada pela ação antrópica (MICHAELIS, 2016). O Bosque dos Capuchinhos consiste em uma área de 20.801,53 m² com vegetação composta de árvores de todos os portes e arbustos, e praça de convivência social, protegida pela Lei Municipal nº 1978, desde 1984. Ijuí se localiza em um ecótono, que divide dois biomas, Pampa e Mata Atlântica, caracterizado por um clima subtropical.

Nessa visita, os alunos devem observar e listar os fatores bióticos e abióticos, além de objetos artificiais. Entre os fatores bióticos, pode-se citar desde algumas árvores nativas e ornamentais encontradas lá, algumas aves, pequenos animais, como formigas, borboletas, aranhas, percevejos, alguns fungos macroscópicos (Basidiomycetes), como cogumelos e orelhas-de-pau. Entre os fatores abióticos, destacamos a luminosidade que varia muito conforme a região do Bosque, presença de rochas (ou não), a umidade, cor e aparência do solo (se parecia ser bem adubado (ou não)) e a presença de gotículas de água nas folhas. Em outras circunstâncias, pode-se aproveitar para coletar um pouco de solo, dissolvê-lo em água e verificar o seu pH, com extrato de repolho roxo, conforme descrito por Gomes (2019). Como objetos artificiais entende-se todos aqueles derivados da ação antrópica, como a própria calçada, embalagens e outros tipos de lixo deixados lá.

Sendo uma atividade problematizadora, ela deve trazer elementos da vida extraescolar dos alunos, valorizando as relações aluno-meio/objeto de estudo (HALMENSCHLAGER; SOUZA, 2012). Também deve determinar o início da SE, ir muito além da "aplicação" de conhecimentos (BOFF et al., 2011), e trazer o aluno através de uma atividade para um contexto real, no qual se inserirão os contextos científicos inclusos no programa escolar.

Nesse momento também é fundamental incentivar os alunos a levantar questões similares observadas por eles no cotidiano, e valorizar todos os comentários advindos disso. Ao dar a devida importância as experiências extraescolares, é possível que os 
alunos vivenciem os conceitos de Biologia, Física e Química em meio a situações reais, bem como sua relevância social, cultural e econômica (BOFF et al., 2011), de modo que o currículo deve ser trabalhado de modo inseparável da cultura (CERNY et al., 2016). O estudo de conceitos disciplinares ocorre, portanto, através de uma situação e perspectiva interdisciplinar dada (HALMENSCHLAGER; SOUZA, 2012), e vinculada ao contexto histórico-sócio-cultural.

\subsubsection{SEGUNDA ETAPA: COMPLEXIFICAÇÃO DE CONCEITOS}

Parte-se da realidade observada no Bosque para a complexificação de conceitos científicos, como fatores bióticos e abióticos. Para tal, solicita-se aos alunos que coletem em casa imagens de fatores bióticos e abióticos para confecção de cartazes em grupo, em sala de aula.

Aproveita-se também para 'trazer o bosque' para dentro da sala de aula. Sendo o bosque um conjunto de ecossistemas, onde ocorrem várias reações fundamentais (fotossíntese, respiração, evapotranspiração, ciclo dos elementos) para a sobrevivência dos seres vivos, sejam eles animais, vegetais ou microrganismos, nada melhor que trazer essa complexidade, em uma escala muito menor, para dentro da sala de aula. Conforme Bedin e Del Pino (2017), é fundamental estabelecer e fortalecer as interações sociais e com o ambiente em que o aluno se encontra, uma vez que o aprendizado ocorre através de trocas de informações e/ou experiências. Desse modo, 'trazer o bosque' para a sala de aula pode fortalecer o vínculo entre os alunos e com o objeto/situação em estudo.

Para tal, a SE deve prosseguir trazendo os alunos como ativos da produção do seu próprio conhecimento, através da montagem do terrário. Para tal, foi solicitado aos alunos que coletassem em casa, no jardim ou a noite embaixo do bico de luz, artrópodes não-peçonhentos, como formigas, grilos, besouros, piolhos de cobra, além de musgos e pequenas plantas para constituição de um terrário.

Um terrário corresponde a um 'mini ecossistema', considerando como ecossistema um conjunto de comunidades que vivem e interagem em contato com os fatores abióticos adequados (ODUM, 2015). Portanto, o terrário é uma atividade que auxilia na formação da consciência crítica dos alunos em relação a problemas ambientais, a partir da abordagem científica, e o reconhecimento de interações entre 
aspectos ambientais e o dia-a-dia (VERONEZ et al., 2009). Devido a fase de progressiva ampliação da autonomia de ação e pensamento em que se encontram os alunos, durante a pré-adolescência, é fundamental a realização de atividades que possibilitem dirigir essas capacidades para a formação científica (BRASIL, 2018). Desse modo, a realização do terrário pode vir a auxiliar nessa tarefa.

A partir do terrário é possível trabalhar fotossíntese, respiração, evapotranspiração e ciclo da água, pode-se também trabalhar noções ecológicas, como o conceito de ecossistema, habitat, nicho, cadeia alimentar e interações, mediante a observação do comportamento dos animais nesse espaço. Para tal, é fundamental destacar que o terrário não deve ser uma atividade pontual e isolada, mas deve ser monitorada a cada aula, e cada observação deve subsidiar o trabalho dos próximos conceitos.

Todos os aspectos citados devem ser contemplados em conversas guiadas, para evitar que o professor em atividade não seja ‘saturado' de questionamentos. Propõe-se começar a dirigir as discussões em prol das reações que são visíveis logo nos primeiros dias, como a formação de gotículas de água na superfície de vidro superior, e daí inserir os conceitos de fotossíntese, respiração e evapotranspiração. Em seguida, com o avançar das aulas, alguns animais inevitavelmente irão morrer. E, nesse momento, deve-se referir aos demais fatores, que não são bióticos, nem abióticos, mas sim sociais (aí vem as interações ecológicas), que também interferem na sobrevivência deles. Desse modo, seguindo uma sequência lógica dos acontecimentos, o professor consegue direcionar o olhar atento dos alunos a atividade, focando no necessário para o momento, mas sem perder a riqueza conceitual que essa atividade oferece.

Além disso, através do terrário deve-se aproveitar para destacar o quanto cada fator biótico e abiótico interfere no todo e, principalmente, como a ausência de algum deles, como água ou luminosidade, pode impactar a sobrevivência de todos os seres. Ressalto que, em meio ao crescente descaso da sociedade em geral (salvo exceções) com a problemática ambiental, é imprescindível aproveitar-se de atividades como tal para mostrar que não existe dano a natureza que não acabe por nos afetar. Pode-se inclusive, usar formigas no terrário, para trabalhar o conceito de sociedade ecológica, e fazer uma analogia as abelhas. Pode-se trazer artigos sobre a redução drástica do número de abelhas, e como isso pode vir a afetar a polinização, consequentemente, 
cultivos vegetais e a população humana. Enfim, em vista da realização do terrário, as possibilidades de se inserir conceitos referentes a ecologia e a educação ambiental são inúmeras.

\subsubsection{TERCEIRA ETAPA: SISTEMATIZAÇÃO DO PROCESSO.}

A SE deve ser sistematizada a partir de uma conversa geral, trazendo uma retrospectiva das atividades desenvolvidas e os conceitos que foram trabalhados a partir delas. Os alunos devem ser incentivados a elaborar um relatório com as atividades desenvolvidas e as principais conclusões advindas delas, e uma conclusão geral do trimestre. Durante a sistematização também é fundamental que o professor aja como um articulador do processo.

\subsection{SEGUNDO MOMENTO: IMPLEMENTAÇÃO DA SE}

A implementação da SE em sala de aula foi acompanhada de encontros com o professor regente da turma no espaço escolar, com frequência de duas a três vezes por semana, para discutir e revisar as atividades a serem desenvolvidas e as questões que poderiam ser abordadas após a atividade. Também foram feitas reuniões semanais com o coletivo de professores em formação inicial de Ciências Biológicas e Química e com as professoras formadoras, no espaço universitário, a fim de potencializar as discussões sobre atividades alternativas para problematização e revisão dos conceitos. Ao todo, somando o período de elaboração, implementação e discussão dos resultados obtidos, foi totalizado 18 reuniões. Enfim, para garantir o melhor aproveitamento da SE e a maior aprendizagem possível aos alunos.

\subsection{TERCEIRO MOMENTO: ANÁLISE DO FEEDBACK DOS ALUNOS DE EDUCAÇÃO BÁSICA}

Após a conclusão das aulas, devido à necessidade de maiores feedbacks pelos alunos, eles foram incentivados a responder questionários semiestruturados, cujas respostas foram tabuladas e analisadas. Para preservar a identidade dos alunos envolvidos, foram utilizados nomes fictícios iniciados com letra A maiúscula. Após, os 
resultados foram sistematizados, comunicados e discutidos junto aos demais professores em formação e as professoras formadoras.

\subsection{QUARTO MOMENTO: ANÁLISE E REFORMULAÇÃO DA SE}

A SE foi reformulada considerando as sugestões feitas pelos alunos de Educação Básica e pela tríade professores formadores - professores em formação inicial professor de Educação Básica (VIEIRA et al., 2018), que também participaram dos encontros prévios.

\section{RESULTADOS E DISCUSSÃO}

\subsection{DESAFIOS NA IMPLEMENTAÇÃO DA SE}

A SE foi implementada em sala de aula, com alunos de sexto ano do Ensino Fundamental e o professor regente, e iniciada com a visita ao Bosque. Nesta saída, foram observados constituintes naturais do ecossistema e também a ação antrópica. Por ser um bosque muito próximo à praça do bairro, existe uma calçada que atravessa lateralmente o Bosque dos Capuchinhos. Marginalmente a essa calçada foram encontradas muitas embalagens de comida, papel de bala, chiclete, pirulito, salgadinho e latinhas de refrigerante.

Posteriormente, em sala de aula, os fatores bióticos a abióticos, assim como os objetos artificiais, decorrentes da ação antrópica foram escritos no quadro negro. Em seguida, os fatores bióticos e abióticos foram distribuídos aos alunos, de modo que cada um ficou responsável por fazer uma breve pesquisa e socializar com os colegas. Estas apresentações foram seguidas de discussões, tanto por parte da professora em formação inicial, quanto por parte do professor regente e dos colegas.

O contexto da visita ao bosque também foi utilizada para iniciar o estudo dos fatores bióticos e abióticos em outras realidades. Para tal, foi solicitado que buscassem e trouxessem para sala de aula imagens de tais fatores (abióticos: fotos representativas de luminosidade, cores/tipos de solo, vento, água e rochas; bióticos: fotos de animais, plantas, fungos, desde bolores até orelhas-de-pau e cogumelos) os quais seriam separados e identificados com nomes populares e acessíveis em cartazes. 
Como a intenção era trabalhar de forma contextualizada, interdisciplinar, prática e reflexiva, tentou-se sempre trabalhar os conceitos aproveitando a realidade vivenciada a partir das atividades práticas e das visitas realizadas neste período. Afinal, a interdisciplinaridade é tão importante quanto a contextualização. A contextualização permite a inserção dos conceitos em uma situação do cotidiano, enquanto a interdisciplinaridade permite a visão global do conhecimento, sem a fragmentação decorrente da disciplinaridade. Em favor da interdisciplinaridade, Morin (2015, p.79) argumenta que "a ciência tornou-se cega pela sua incapacidade de controlar, prever e mesmo de conceber o seu papel social, pela sua incapacidade de integrar, articular, refletir seus próprios conhecimentos". O ensino de Ciências é ideal para agir como um laboratório da interdisciplinaridade (MACKEDANZ; ROSA, 2016). A SE por sua vez, supera a concepção linear do saber (RITTER; MALDANER, 2015), não se limita a uma disciplina e, portanto, evita a ruptura do conhecimento (BEDIN; DEL PINO, 2017).

Para tal, partindo da vivência com o bosque, os alunos foram incumbidos de trazer artrópodes não-peçonhentos, como formigas, grilos, gafanhotos, besouros, além de musgos e pequenas plantas para confecção do terrário. Um terrário é uma miniatura de ecossistema com o intuito de possibilitar a observação de fenômenos que ocorrem no bosque em menor escala. Para realização desta atividade, foi utilizado um terrário antigo, no qual foi acrescentado terra, carvão, água, plantas e animais que haviam sido solicitados aos alunos. Este processo envolveu os alunos, de modo que todos puderam 'colocar a mão na massa'. A confecção do terrário mostrou-se uma atividade rica, uma vez que resultou em muitos questionamentos que acabaram norteando a abordagem dos próximos conteúdos.

O terrário não foi uma atividade pontual, que seria realizada e depois abandonada. Através do seu monitoramento semanal, ele contribuiu para a aprendizagem de conceitos. Para aprendizagem efetiva, conceitos precisam ser revistos e retomados algumas vezes (VIEIRA et al., 2018). Desse modo, em uma SE, através do uso de diversas atividades, os conceitos surgem e ressurgem, e a sua discussão em sala de aula permite que a compreensão evolua progressivamente (HALMENSCHLAGER; SOUZA, 2012). 
Neste ponto, chamou-se atenção para os três processos principais envolvidos na sobrevivência do terrário, evapotranspiração, fotossíntese e respiração, além do ciclo da água, que foi identificado pela formação de gotículas na parte superior do terrário. Tais conceitos foram trabalhados de forma tradicional, utilizando-se esquemas demonstrativos na lousa, assim como exemplificações no próprio terrário. Especificamente, trabalhar com a fotossíntese mostrou-se bastante complexo para alguns dos alunos, haja visto os diferentes termos utilizados e o emaranhado de fórmulas químicas. Daí, surgiu a ideia de elaborar um glossário com cinco folhas de ofício dobradas ao meio, no formato de 'caderno' com 10 folhas de tamanho reduzido. Cada folha foi usada na sua frente e verso. Este glossário foi organizado pelas letras A, B, C, D, E, F/G, H/I/J/K, L, M, N/O, P/Q, R, S, T, U/V, X/Y/W/Z, e facilitou a familiarização com os termos científicos, conforme a tabela 1 .

Tabela 1: Esquema representativo da organização do glossário.

\begin{tabular}{|c|c|}
\hline $\begin{array}{c}\text { Folha } 1 \text {-frente } \\
\text { CAPA - GLOSSÁRIO }\end{array}$ & $\begin{array}{c}\text { Folha } 1-\text { verso } \\
\text { CAPA } \\
\text { Nome do aluno, disciplina, } \\
\text { professor e ano }\end{array}$ \\
\hline $\begin{array}{c}\text { Folha } 2 \text {-frente } \\
\text { Letra A }\end{array}$ & $\begin{array}{c}\text { Folha } 2-\text { verso } \\
\text { Letra B }\end{array}$ \\
\hline $\begin{array}{c}\text { Folha } 3 \text {-frente } \\
\text { Letra C }\end{array}$ & $\begin{array}{c}\text { Folha } 3 \text { - verso } \\
\text { Letra D }\end{array}$ \\
\hline $\begin{array}{c}\text { Folha } 4 \text {-frente } \\
\text { Letra E }\end{array}$ & $\begin{array}{c}\text { Folha } 4 \text { - verso } \\
\text { Letras F/G }\end{array}$ \\
\hline $\begin{array}{l}\text { Folha } 5 \text {-frente } \\
\text { Letras } \mathrm{H} / \mathrm{I} / \mathrm{J} / \mathrm{K}\end{array}$ & $\begin{array}{c}\text { Folha } 5 \text { - verso } \\
\text { Letra L }\end{array}$ \\
\hline $\begin{array}{c}\text { Folha } 6 \text {-frente } \\
\text { Letra M }\end{array}$ & $\begin{array}{c}\text { Folha } 6-\text { verso } \\
\text { Letras N/O }\end{array}$ \\
\hline $\begin{array}{c}\text { Folha } 7 \text {-frente } \\
\text { Letras P/Q }\end{array}$ & $\begin{array}{c}\text { Folha } 7 \text { - verso } \\
\text { Letra } \mathrm{R} \\
\end{array}$ \\
\hline $\begin{array}{c}\text { Folha } 8 \text {-frente } \\
\text { Letra } S\end{array}$ & $\begin{array}{c}\text { Folha } 8 \text { - verso } \\
\text { Letra T }\end{array}$ \\
\hline $\begin{array}{c}\text { Folha } 9 \text {-frente } \\
\text { Letras U/V }\end{array}$ & $\begin{array}{l}\text { Folha } 9-\text { verso } \\
\text { Letras } \mathrm{X} / \mathrm{Y} / \mathrm{W} / \mathrm{Z}\end{array}$ \\
\hline $\begin{array}{c}\text { Folha } 10 \text {-frente } \\
\text { CAPA e demais } \\
\text { anotações pertinentes }\end{array}$ & $\begin{array}{c}\text { Folha } 10 \text { - verso } \\
\text { CAPA e demais anotações } \\
\text { pertinentes }\end{array}$ \\
\hline
\end{tabular}

Neste ponto, a partir do terrário, era previsto estudar a fórmula, distribuição, estados físicos e ciclo da água. Ela foi precedida de questionamentos, que indicaram o alto nível de conhecimento dos alunos, e o fato de já terem estudado isso. Diante do imprevisto, a problematização se mostrou benéfica para o desenvolvimento das 
atividades em sala de aula, impedindo que houvesse repetição desnecessária e ociosidade.

Gama e Duarte (2017) refletem sobre a necessidade de reorganização curricular em pró de atender as reais necessidades dos alunos enquanto sujeitos históricos e sociais. Nesse contexto, os autores salientam que, um dos principais aspectos determinantes nesse processo, é o fato de saber dosar e sequenciar os conteúdos durante o tempo-espaço disponível, o que implica estar atento a necessidade de explicar mais ou menos determinados conceitos.

A partir da monitoria do terrário também foi observado que algumas formigas acabaram morrendo devido a características comportamentais, pois são animais sociais, que necessitam viver em grupos organizados em rainhas, machos e operárias (GORDON, 2002). Sem essa organização, mesmo com adequada disponibilidade de água, oxigênio, $\mathrm{CO}_{2}$ e alimento, a sua sobrevivência a longo prazo (aproximadamente quatro semanas) não foi viável. Essa observação gerou discussões que possibilitaram o trabalho das interações ecológicas nesse contexto, como o conceito de sociedade ecológica. Portanto, a utilização das formigas no terrário, embora elas inevitavelmente venham a morrer ao longo da atividade, não representa um dilema ético, mas sim, uma oportunidade para estudar e vivenciar as interações ecológicas em sala de aula. Além disso, aproveitou-se a oportunidade para, conforme havia sido considerado no momento de elaboração da SE, citar as abelhas como também sendo animais sociais, fundamentais para a polinização, e para a sobrevivência de todos os demais seres, inclusive dos humanos. Tendo isso em consideração, na aula seguinte, os conceitos das interações foram retomados.

Dando continuidade e ressaltando a importância dos alunos manterem seu glossário atualizado, chamou-se a atenção para algumas interações, como predatismo e herbivoria para iniciar o trabalho da cadeia alimentar. Questionando e discutindo sobre a expressão 'cadeia alimentar', ficou evidente que eles já haviam trabalhado anteriormente sobre cadeia alimentar. Então, foi elaborada uma apresentação de slides sobre esse assunto, dando especial enfoque para os nichos ecológicos e para o fluxo de matéria e energia. Todas as apresentações foram ricas em imagens, uma vez que se trata de mais um recurso potencializador da aprendizagem. 
Em seguida, chamou-se a atenção para outro fator indispensável para um ecossistema, o solo. No Plano de Trabalho de Ciências não era previsto trabalhar com o solo naquele momento. No entanto, devido à realização do terrário e da vastidão conceitual que sua observação permitiu abordar, julgou-se adequado aproveitar o momento para trabalhar os tipos de solo. Isso vai ao encontro dos preceitos da SE, que defendem que a SE embora seja elaborada e estudada com base no Plano de Trabalho original, não é estática. A SE é uma alternativa de ensino dinâmica, em constante estudo, que usa diferentes metodologias e não apresenta uma linearidade (VIERA et al., 2018). Além disso, também apresenta-se em permanente reconstrução (BOFF et al., 2011), assim como os envolvidos, em constante desenvolvimento e reconstruindo saberes (FREIRE, 2002). Tais características possibilitam a sua adequação, e a reorganização de conceitos conforme a sua contribuição na compreensão do contexto estudado (HALMENSCHLAGER; SOUZA, 2012), e os momentos surgidos em sala de aula.

Para iniciar os trabalhos, foi realizada uma atividade prática envolvendo a utilização de garrafas Pet, solo argiloso, humoso e arenoso, água e sementes. Parte deste material foi solicitada aos alunos, os demais foram disponibilizados pelo laboratório da escola. Nesta atividade prática, foram cortadas as garrafas na metade, de modo a preencher três de solo argiloso, dois de humoso (pois não havia solo suficiente) e três de arenoso. Cada tipo de solo teve o seu correspondente úmido, seco e encharcado. Para manter o solo úmido foi adotado o modelo de vaso auto irrigável, em que foram acoplados fios de barbante na metade da garrafa contendo solo, e que entram em contato com a outra metade da garrafa posicionada inferiormente, cheia de água (CREMASCO et al., 2018). Nesse modelo de vaso auto irrigável a água sobe pelo barbante pelo princípio de capilaridade (CREMASCO et al., 2018).

Esta prática envolveu bastante dedicação por parte da professora em formação inicial e do professor regente, uma vez que ela não tinha sido feita anteriormente por nenhum dos dois. Logo, foi preciso pesquisar em vídeos, fotos e protocolos disponíveis online. O trabalho de Cremasco e colaboradores (2018), auxiliou bastante nessa tarefa, e pode facilitar o trabalho de professores que possam vir a desenvolver essa SE novamente. Destaco que, apesar de ter demandado dedicação dos professores, porque 
não detínhamos as referências necessárias, a experiência foi válida para ambos, e para os alunos, que se envolveram bastante. Além disso, por ser uma atividade prática que requer materiais de fácil acesso (embora alguns estivessem disponíveis no laboratório, ela pode ser uma boa alternativa em casos em que a infraestrutura da escola é um fator limitante, conforme traz Henzel (2019).

Ao longo da implementação da SE, foram tomadas as precauções para que os alunos detivessem o conhecimento necessário para participar de cada atividade prática, uma vez que as observações e discussões possibilitariam o trabalho e entendimento dos conceitos. Portanto, todas as atividades foram precedidas e sucedidas de discussões e questionamentos, a fim de estimular os alunos a formular hipóteses e explicações para os fenômenos observados.

\subsection{AVALIANDO O FEEDBACK DOS ALUNOS DE EDUCAÇÃO BÁSICA}

Diante do feedback dos alunos e das discussões advindas nesse processo, é possível fazer ajustes na SE e melhorá-la para novas implementações em trimestres e/ou em turmas subsequentes (BOFF et al., 2011). Para tal, após a conclusão das aulas, os alunos responderam questionários semiestruturados. Com base nesses resultados e nos comportamentos observados, pode-se afirmar que as atividades e a forma como os conceitos foram empregados tiveram a aprovação dos alunos.

Quando questionados previamente a realização de alguma atividade prática, os alunos se sentiram entusiasmados em responder e em mostrar o que já sabiam. Foi evidente o quanto eles ansiaram pelas atividades, e de fato foi quando os professores mais detiveram a atenção dos alunos. Também foi evidente o quanto uma alternativa de ensino como a SE, que utiliza diferentes metodologias e ferramentas de ensino, pode ser mais benéfica ao trabalhar principalmente com crianças, porque o conjunto de atividades consegue prender mais a sua atenção e eles conseguem empregar a sua energia em algo proveitoso.

Portanto, quando questionados sobre as formas com as quais eles mais aprendem, as respostas vieram ao encontro do que foi trazido pela SE, mostrando grande aceitabilidade quanto a sua implementação. As saídas a campo foram consideradas requisitos para boas aulas de Ciências. Almir afirmou que uma boa aula de Ciência é "aquela que tem saídas para outros lugares". Ângelo e Aline foram mais específicos e 
trouxeram que uma boa aula de Ciência é "Quando saímos ao bosque", "Que nós vamos ao bosque", respectivamente. Outros estudantes como Alex e Alyson tiveram opiniões mais amplas, trazendo que uma boa aula de Ciência é "Saída a campo" e que "A que vamos viajar", respectivamente.

Os depoimentos mostram grande aprovação pela atividade problematizadora da SE. De acordo com os alunos, saídas a campo são fundamentais para a visualização dos objetos de estudo e, portanto, possibilitam a visão geral prévia do que será trabalhado em seguida. Essas afirmações evidenciam que as aulas de Ciências devem ser desenvolvidas com base em um contexto real do estudante, no caso, a mata, que contribui para despertar a curiosidade pelo ensino de Ciências (BEDIN; DEL PINO, 2017). A partir desse momento, a curiosidade ingênua pode ser transformada em curiosidade epistemológica, que caracteriza a reconstrução do conhecimento popular para o conhecimento científico (FREIRE, 2002). E por consequência, nesse processo de ensino os conceitos espontâneos (do cotidiano) são reconstruídos e transformados em conceitos eruditos (VYGOTSKY, 2000).

Apesar dos benefícios da saída a campo, a SE não pode ser restrita a isso. Muito pelo contrário, a SE deve contemplar diferentes atividades, práticas e teóricas que atendam aos diferentes objetivos. Nesse sentido, Angélica concorda com essas afirmações, uma vez que tem facilidade de aprender quando "a aula tem atividades diferentes."

A SE visa contemplar o mesmo conceito várias vezes, sob perspectivas, contextos e atividades diferentes, que possibilitam que estes estejam permanentemente em recontextualização, significação e evolução (RITTER et al, 2018). A elaboração e implementação da SE tem como premissa máxima a não linearidade do entendimento (GAMA; DUARTE, 2017). É por essa razão que, mediante a utilização de várias SEs e várias atividades diferentes, que ao avançar entre as séries do Ensino Fundamental, além do aluno se apropriar de mais conceitos, ele também os compreende de forma progressivamente mais profunda e complexa (GAMA; DUARTE, 2017).

As demais atividades práticas também foram citadas positivamente pelos alunos, como Angélica que afirmou que uma boa aula de Ciências é "Uma aula com experiências", e Anderson que afirmou que uma boa aula de Ciências é "aula com 
atividades e brincadeiras". Os depoimentos tornam claro a necessidade de diferentes atividades que contentem todos os públicos e que se complementem. Diferentes atividades e abordagens devem atender problemas que tendem a ser distintos entre os alunos, e que devem surgir ao longo das discussões (RITTER; MALDANER, 2015). A utilização de uma grande variedade de métodos em sala de aula também é defendida pelos PCN de Ciências Naturais, segundo os quais “diferentes métodos ativos (...) despertam o interesse dos estudantes pelos conteúdos e conferem sentidos à natureza e à ciência que não são possíveis ao se estudar Ciências Naturais apenas em um livro (p. 27).

É inegável que a utilização de atividades práticas contribui para a atração dos alunos para o contexto e os conceitos trabalhados. Todavia, esse não é o objetivo principal da SE, é apenas o meio utilizado para alcançá-lo. O objetivo central da SE é promover o aprendizado com base na constituição do aluno enquanto sujeito ativo e interativo na produção do seu próprio conhecimento, enquanto um pesquisador (BOFF et al., 2011), de acordo com os preceitos de Vygotsky (2000).

Assim, torna-se óbvio que alcançamos a meta principal do trabalho no momento em que, quando questionado sobre como seria uma aula ideal, a aluna Alana respondeu aquela "que tem pesquisa".

\subsection{A IMPORTÂNCIA DA CONTÍNUA ANÁLISE E REFORMULAÇÃO DA SE}

A adaptação e melhoria da SE baseada nas sugestões é o momento mais importante. Para tal, é fundamental que todos os professores, coordenadores e a diretoria da escola estejam dispostos a propiciar um espaço de diálogo reconstrutivo, que possibilite a inovação (BOFF et al., 2011, VIEIRA et al., 2018).

Além disso, a reorganização curricular depende não somente dos professores, mas também dos alunos (BEDIN; DEL PINO, 2017). Depende, especialmente, de intensa interação entre os sujeitos envolvidos, e da reflexão tendo a própria prática como objeto de estudo (BAKHTIN, 2006). Esse processo permite novas interpretações e concepções sobre o papel da Ciência na sociedade e, consequentemente, a reorganização curricular (MALDANER, 2006). Momentos de interação como esses, em geral, resultam em mudanças significativas nas concepções dos envolvidos, em favor dos benefícios da SE (BEDIN; DEL PINO, 2017), pois, independentemente da área de interesse, o saber é 
sempre uma construção coletiva, resultado de discussões entre seres sociais (TARDIF, 2002).

Com base nos depoimentos dos alunos trazidos anteriormente, ficou claro que as atividades utilizadas foram bem escolhidas e empregadas, e o quanto as discussões anteriores e posteriores as atividades foram fundamentais para o sucesso destas.

A partir da implementação da SE, foi perceptível a principal limitação que foi o excesso de termos científicos utilizados nas explicações. Nessa perspectiva, a elaboração do glossário foi fundamental, pois somente assim os alunos conseguiram realmente se organizar. De fato, algumas teorias científicas são mais difíceis de serem aprendidas por alunos de ensino fundamental, pois são muito distantes do senso comum, e abstratas (PCN, 1998). Portanto, demandam mais energia para criação de formas que possibilitem esse processo (PCN, 1998).

Desse modo, sugeriu-se inserir a elaboração do glossário enquanto atividade da SE. Essa atividade pode iniciar logo após a atividade de problematização (Visita ao Bosque), ou a qualquer momento das aulas em que os professores julgarem necessário.

Durante a implementação da SE também foi oportuno abordar conceitos de solo a partir do terrário, e dando prosseguimento a outra atividade prática, com utilização do modelo de solo auto-irrigável. Com base nas discussões entre a tríade, julgou-se melhor aderir a essa modificação na SE. Desse modo, a conformação final da SE está descrita na tabela 2.

Tabela 2: Estruturação final da SE.

\section{PRIMEIRA ETAPA: Problematização}

Atividade 1: visita ao Bosque dos Capuchinhos.

Observar e listar os fatores bióticos, abióticos e objetos artificiais observados em um bosque (conforme descrito previamente).

SEGUNDA ETAPA: Complexificação dos conceitos

Estudo de fatores bióticos e abióticos.

Atividade 2: Cartaz

Trazer de casa imagens referentes a fatores bióticos e abióticos para confecção de cartaz comparativo (fatores bióticos $v s$ abióticos), no coletivo em sala de aula.

Ecossistema, fotossíntese, ciclo da água e interações ecológicas.

Atividade 3: Terrário

Montagem de terrário em uma caixa de vidro 
Colocar uma camada de $3 \mathrm{~cm}$ de pedrinhas, $3 \mathrm{~cm}$ de areia e, aproximadamente, $5 \mathrm{~cm}$ de terra com húmus. Após, plantar as mudinhas trazidas de casa, e soltar os artrópodes. O terrário deve ser regado a fim de fornecer a umidade inicial necessária, vedado, e posicionado em local ensolarado.

Atividade 4: Glossário

Dobrar cinco folhas de ofício ao meio, de modo a formar um 'caderno'. Distribuir o espaço pelas letras: A, B, C, D, E, F/G, H/I/J/K, L, M, N/O, P/Q, R, S, T, U/V, $\mathrm{X} / \mathrm{Y} / \mathrm{W} / \mathrm{Z}$. Utilizar a tabela 1 como sugestão para organização.

\section{Solo}

Atividade 5: Tipos de solo

Cortar seis garrafas Pet aproximadamente pela metade. Preencher a metade das garrafas com solo argiloso, humoso e arenoso (três garrafas para cada solo). Cada solo deve ter seu correspondente seco e úmido. Para obtenção do solo úmido, utilizar o modelo de vaso auto irrigável, em que foram acoplados fios de barbante na metade da garrafa contendo solo, e que entram em contato com a outra metade da garrafa posicionada inferiormente, cheia de água. Nesse modelo de vaso auto irrigável a água sobe pelo barbante pelo princípio de capilaridade (CREMASCO et al., 2018).

\section{TERCEIRA ETAPA: Sistematização}

Atividade 6: Relatório englobando as atividades desenvolvidas e as principais conclusões advindas delas, e uma conclusão geral do trimestre.

O processo desde a elaboração até a reformulação da SE, possibilitou apresentar uma alternativa de reorganização curricular, para trabalhar com conteúdo de ciências vinculado a natureza. Além disso, os encontros ocorridos ao longo desse estudo evidenciam o quanto tal processo demanda comprometimento de ambas as partes envolvidas, além de contato contínuo para possibilitar as interações necessárias para a construção do conhecimento e da SE, propriamente dita. Através de grupos engajados na pesquisa pela melhoria do ensino, que contemplem universidades e escolas, bem como interfaces entre elas, é possível marchar na contramão da prática tradicional cognitivo-instrumental dominante, em prol de uma prática alternativa, ainda pouco estudada. Como ressalta Cerny et al. (2016, p. 10), embora muitos critiquem o ambiente escolar na tomada de medidas, "quando um coletivo escolar opta por mudanças acordadas coletivamente, a possibilidade de transformação torna-se enorme”.

$\mathrm{Na}$ tentativa de superar a fragmentação e a forma linear em que na maioria das vezes os conteúdos são abordados, por processo reflexivo, diversas tentativas inovadoras de reorganização curricular são desenvolvidas via pesquisa. Assim, 
intervenções curriculares na perspectiva da abordagem temática favorecem o repensar do docente sobre o papel que desempenha na sociedade (FERREIRA et al., 2019). Evidenciou-se nesta pesquisa as potencialidades da SE, tanto na constituição do professor em formação inicial quanto para o professor em formação continuada, de modo que esta forma de reorganização curricular apresenta êxito e possibilita a reflexão sobre a pratica pedagógica.

\section{CONSIDERAÇÕES FINAIS}

As potencialidades da SE residem em promover o aprendizado contextualizado e aplicável à vida extraescolar. Portanto, é necessário aos professores estarem atentos as discussões geradas em sala de aula, para perceber aspectos que não precisam ser reestudados, ou que cabem ser estudados naquele momento. Isto é, embora a SE seja elaborada com base nos conceitos planejados, ela não é estática, e deve ser adaptada conforme as necessidades. Concluímos com base no feedback dos alunos e nas discussões na tríade, que as atividades foram bem empregadas e que atenderam aos objetivos propostos para as aulas. Com base nos depoimentos dados pelos alunos, concluímos que implementação da SE foi efetiva para a sua constituição enquanto sujeitos ativos na produção do seu conhecimento a partir da pesquisa e auxiliou na construção da sua consciência crítica quanto a problemática ambiental.

Conflito de interesse: Os autores declaram não ter conflito de interesse.

Agência de fomento: A pesquisa não teve fomento.

\section{REFERÊNCIAS}

BAKHTIN, M. Marxismo e filosofia da linguagem. 11 ed. SP: Editora Hucitec. (Traduzido), 2006.

BEDIN, E. DEL PINO, J. C. Concepções de professores sobre Situação de Estudo: rodas de conversa como práticas formadoras. Interfaces da Educação, v.8, n.22, p.154$185,2017$.

BOFF, E. T. O. et al. Ambiente e Vida - o ser humano nesse contexto: uma estratégia de ensino transformadora do currículo escolar. Revista Eletrônica do Mestrado em Educação Ambiental, v. 26, p. 306-321, 2011.

BRASIL. Secretaria de Educação Fundamental. Parâmetros Curriculares Nacionais (PCNs): Ciências Naturais/ Secretaria de Educação Fundamental. Brasilia: MEC/ SEF, 1998, 138 p. 
BRASIL. Base Nacional Comum Curricular (BNCC). Educação é a Base. Brasília, MEC/CONSED/UNDIME, 2018.

CERNY, R.Z. et al. O currículo na cultura digital: impressões de autores de materiais didáticos para formação de professores. Revista Educação Pública, v. 25, n. 59, p. 341-353, 2016.

COSTA-BEBER, L. C. et al. Ensino e formação escolar: algumas implicações de modelos de ensino vivenciados em processos educativos. Revista SBEnBIO, n.7, p. 4806-4817, 2014.

CREMASCO, C. P. et al. Utilização de materiais recicláveis na construção de equipamentos de irrigação. Revista Ciência e Extensão, v. 14, n. 4, 2018.

FERREIRA, M. V. et al. Desafios e potencialidades em intervenções curriculares na perspectiva da abordagem temática. Revista Ensaio: Pesquisa em Educação em Ciências, Belo Horizonte, v. 21, 2019.

FREIRE, P. Pedagogia da autonomia: saberes necessários à prática educativa. $25^{\mathrm{a}}$ ed. Editora Paz e Terra, 2002.

GAMA, C. N.; DUARTE, N. Concepção de currículo em Dermeval Saviani e suas relações com a categoria marxista de liberdade. Interface, v. 21, n. 62, p. 521-530, 2017.

GOMES, D. S. O uso da experimentação no ensino das aulas de ciências e biologia. Revista Insignare Scientia, v. 2, n. 3, p. 103-108, 2019.

GORDON, D. Formigas em ação: como se organiza uma sociedade de insetos. Ed. Jorge Zahar, 2002.

GÜNZEL, R. E. Ensinar é Aprender: Desafios e Experiências no Estágio de Docência. Revista Insignare Scientia, v. 2, n. 3, p. 222-232, 2019.

HALMENSCHLAGER, R. K.; SOUZA, C. A. Abordagem temática: uma análise dos aspectos que orientam a escolha de temas na Situação de Estudo, Investigações em Ensino de Ciências, v. 17, n. 2, p. 367-384, 2012.

HENZEL, T. L. A utilização da experimentação na sala de aula. Revista Insignare Scientia, v. 2, n. 3, p. 323-330, 2019.

MACKEDANZ, L. F.; ROSA, L. S. O discurso da interdisciplinaridade e as impressões docentes sobre o ensino de Ciências Naturais no Ensino Fundamental. Revista Thema, v. 13, n. 3, p. 140-152, 2016.

MALDANER, O. A. A formação inicial e continuada de professores de química: professores/pesquisadores. 3 ed. Ijuí. Ed. Unijuí, 2006.

MALHOTRA, N. Pesquisa de marketing: uma orientação aplicada. 4. ed. Porto Alegre, RS: Bookman, 2006.

MICHAELIS. Dicionário Escolar de Língua Portuguesa. 4 ed. São Paulo, Ed. Melhoramentos, 2016.

MORIN, E. Os sete saberes necessários à educação do futuro. 3 ed. São Paulo, SP: Cortez; Brasília, DF: UNESCO, 2001. 
MORIN, E. Introdução ao pensamento complexo. 5 ed. Porto Alegre: Ed. Sulina, 2015.

ODUM, E. P. Fundamentos de ecologia. 5 ed. São Paulo: Ed. Cengage Learning, 2015.

Rio Grande do Sul. Lei Municipal no 1978, de 01 de março de 1984. Cria o Parque Municipal "Bosque dos Capuchinhos" e proíbe o abate, a retirada e a comercialização de espécies nativas vegetais em sua área de jurisdição. Ijuí, 1984. Disponível em: https://leismunicipais.com.br/a/rs/i/ijui/lei-ordinaria/1984/197/1978/lei-ordinaria-n1978-1984-cria-o-parque-municipal-bosque-dos-capuchinhos-e-proibe-o-abate-aretirada-e-a-comercializacao-de-especies-nativas-vegetais-em-sua-area-de-jurisdicao. Acesso em: novembro de 2019.

RITTER, J.; MALDANER, O. A. CTS na Situação de Estudo: desenvolvimento de currículo e formação de professores. Praxis e Saber, v. 6, n. 11, p. 195-214, 2015.

RITTER, J. et al. Núcleos de Pesquisa na Escola: possibilidades de mudanças didáticas e práticas de ensino dos professores. Revista de Didácticas Específicas, n. 18, p. 167186, 2018.

SANGIOGO, F. A. et al. A. Pressupostos epistemológicos que balizam a situação de estudo: algumas implicações ao processo de ensino e à formação docente, Ciências \& Educação, v.19, n.1, p.35-54, 2013.

SAVIANI, D. Educação: do senso comum à consciência filosófica. $15^{\mathrm{a}}$ ed. Campinas: Autores Associados, 2004.

TARDIF, M. Saberes docentes e formação profissional. 14. ed. Petrópolis, RS: Vozes, 2002.

VERONEZ, W. M. et al. A utilização do terrário para conscientização ambiental de estudantes do ensino básico. Revista Brasileira de Ensino de Ciência e Tecnologia, v. 2, n. 3, 2009.

VIEIRA, L. B. G. et al. Situação de Estudo: o que vem sendo publicado em eventos e periódicos da área de Ensino de Ciências? Revista Ensaio, v.20, p. 1-29, 2018.

VYGOTSKY, L. S. A Construção do Pensamento e da Linguagem. São Paulo: Martins Fontes, 2000. 